\title{
Teaching surgical skills in obstetrics using a cesarean section simulator - bringing simulation to life
}

This article was published in the following Dove Press journal:

Advances in Medical Education and Practice

3 December 2010

Number of times this article has been viewed

\author{
Venkata Sujatha Vellanki' \\ Sarath Babu Gillellamudi ${ }^{2}$ \\ 'Department of Obstetrics and \\ Gynaecology ${ }^{2}$ Department of General \\ Surgery Kamineni Institute of Medical \\ Sciences, Sreepuram, Narketpally, \\ Nalgonda, Andhra Pradesh, India
}

Purpose: Cesarean section is the most common surgery performed in obstetrics. Incorporating a simulation model into training provides a safe, low-stress environment in which students can gain skills and receive feedback. The purpose of this study was to determine the effectiveness of obstetrics simulator training for medical students doing their internship.

Methods: Twenty-five students posted in the Department of Obstetrics and Gynecology received a formal lecture on cesarean section and demonstration of the procedure on a mannequin in the first week of their internship, The study group $(n=12)$ practiced their skills on an obstetrics simulator under the direct supervision of a faculty member. The control group received no simulator-based training $(n=13)$ or further instruction. All students were asked to complete a prevalidated questionnaire to assess their level of confidence in performing the procedure after the educational session.

Results: Compared with their peers in the study, students in the simulator group were significantly more likely to define the steps of cesarean section ( $91 \%$ vs $61.5 \%)$, and were comfortable in assisting cesarean section ( $100 \%$ vs $46.15 \%$ ) as they were able to identify the layers of abdomen opened during cesarean section. All 12 students reported this as an excellent experience.

Conclusion: We were able to construct an inexpensive cesarean section trainer that facilitates instruction in cesarean section technique in a low-stress environment.

Keywords: simulation, obstetrics, medical students

\section{Introduction}

Surgical education research has been exploring alternative methods of teaching surgical skills that may enhance or accelerate learning. There is good evidence that procedural simulation improves operational performance in actual clinical settings. ${ }^{1}$ The training and development of technical skills has largely been performed in the operating room. Although most institutions in the West and Tanzania under low resource settings ${ }^{2}$ have implemented surgical skills training programs for surgical residents, few such programs exist in India. In the current model of surgical training, based primarily on apprenticeship, the opportunities for deliberate practice are rare. Operations are complex, and it is difficult to focus on one small component of the procedure. ${ }^{3}$ As surgical techniques become more advanced, the content of surgical training in obstetrics and gynecology is becoming increasingly complex. For example, compared with laparotomy, minimally invasive laparoscopic surgery requires the trainee to develop spatial relationship skills and associated psychomotor skills to be able to manipulate surgical instruments in a 3-dimensional operative field while looking at a 2 -dimensional video screen. Therefore, effective training in obstetrics and gynecology requires skills acquisition in basic and complex surgical techniques and obstetric procedures. All of these skills potentially
Correspondence: Venkata Sujatha Vellank Obstetrics and Gynaecology, Kamineni Institute of Medical Sciences, Sreepuram, Narketpally, Nalgonda, Andhra Pradesh - 508254, India

Tel +9| 86822721 I8

Fax +91 8682272829

Emailsujathavv@yahoo.com 
can be taught and assessed with simulation-based training. ${ }^{4}$ Obstetrical simulation is the re-enactment of routine or critical clinical events involving a woman who is pregnant or recently delivered and her fetus or newborn for procedural or behavioral skills training, practice, evaluation, or research. The overall goal of obstetric simulation is to improve the quality and safety of care for women and newborns. ${ }^{5}$

There are 2 types of surgical simulators. The low-fidelity simulators use material and equipment that are less similar to the true surgical environment. Low-fidelity models sacrifice realism for portability, lower cost, and potential for repetition. Examples of low-fidelity simulators include bench models such as video box trainers, knot tying boards, and episiotomy repair models. The high-fidelity simulator provides realism through characteristics such as visual cues, tactile features, and feedback capabilities. Examples of high-fidelity simulators would include virtual reality simulators, procedural simulators, and live animal models. Live animal models are considered to be of high fidelity and are most desirable for complex skills. Drawbacks to these models are high cost, limited availability, and moral and ethical concerns. Currently available obstetric simulators range from part-task trainers for suturing episiotomy, birthing pelvis for forceps and vaccum application to high-fidelity life-size female mannequins, situations, and environments for realistically representing obstetric events. Our model would be considered as an intermediate to a high-fidelity surgical simulator for training residents in cesarean section. Cesarean section is the most common surgery performed in obstetrics and incorporating a simulation model into training provides a safe, low-stress environment in which students can gain skills and receive feedback. Because we could not identify a commercially available trainer or an adequately described simulation model for this procedure, we developed our own cesarean section model. There were no studies available to determine the effectiveness of such simulation in the literature though one study has shown a similar simulation model on video presentation. ${ }^{6}$ The purpose of this study was to determine the effectiveness of obstetrics simulator training for medical students doing their internship.

\section{Material and methods}

A cesarean section model was made of the various layers of abdomen, uterus and amniotic cavity, and dummy fetus, using fabric available from craft stores (Figures 1 and 2). Approval was obtained from the college research committee. Twenty-five students posted in the Department of Obstetrics and Gynecology received a formal lecture on cesarean section and demonstration of the procedure on the mannequin in the
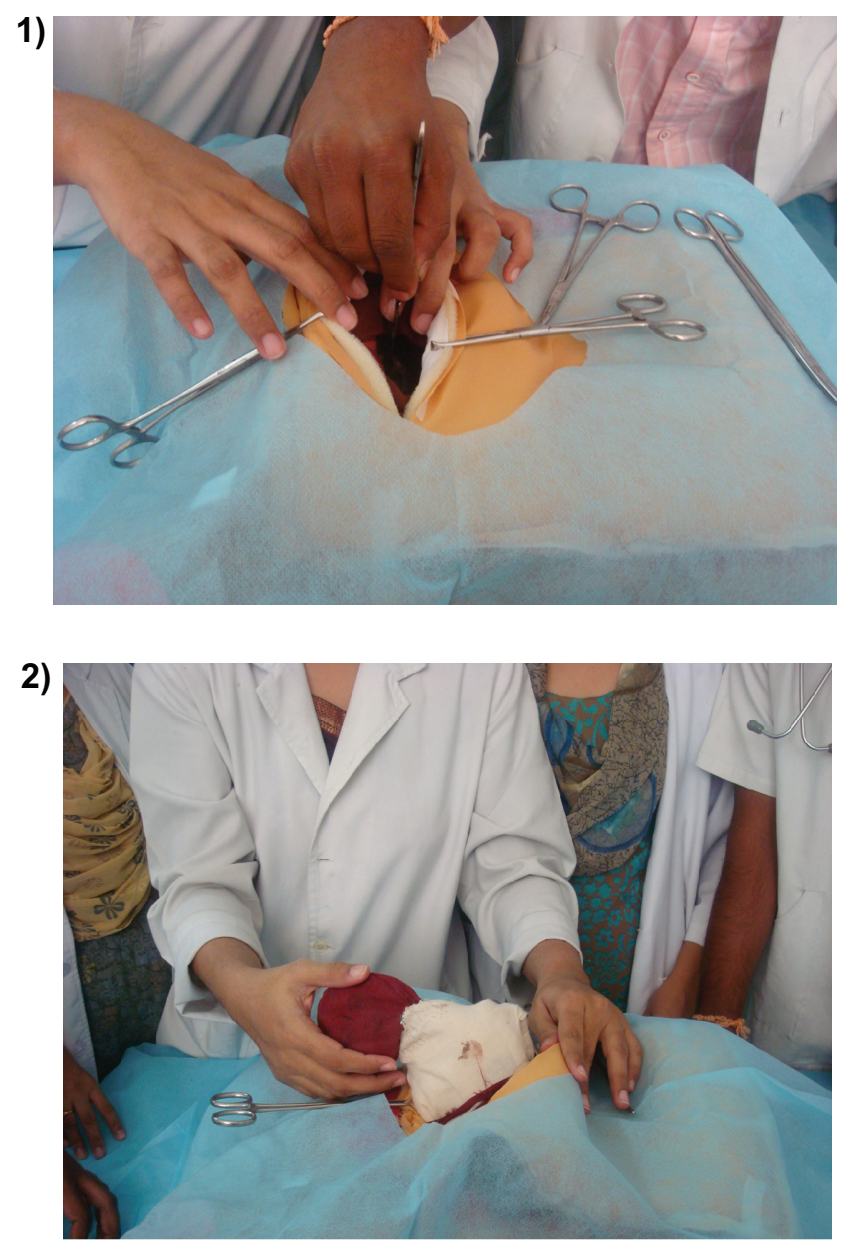

Figure I and $\mathbf{2}$ The layers of abdomen and dummy fetus being delivered during the procedure.

first week of their internship. This sample size was selected as students are posted in the department in batches of 12 to 13 . The simulator study group $(\mathrm{n}=12)$ practiced their skills on an obstetrics simulator under the direct supervision of a faculty member. The control group received no simulator-based training $(\mathrm{n}=13)$ or further formal instruction.

All students were asked to complete a prevalidated questionnaire to assess their level of confidence in performing the procedure immediately after the educational session. The following steps were followed in prevalidating the questionnaire. The questions were framed keeping in mind the objectives of the study. They were discussed with the experts in the department and modifications were done. The questionnaire was pilot tested on 15 senior residents not involved in this study and were asked to give their feedback. The time taken to fill the questionnaire and their feedback was taken. Analysis of reliability of the questionnaire was done with SPSS software. The final questionnaire was made after deleting the questions of low reliability. The questionnaire includes 13 closed ended questions to measure self-perceived confidence in performing 
the steps of cesarean section. Students rated their confidence on a five-point Likert scale, 1) 'Very unconfident' to 5) 'Very confident'. Qualitative questions on how the training changed student perception of performing surgery as well as recommendations for improvement of the training were also included in the questionnaire. Responses for each item in the questionnaire were compared between both the groups. Data were analyzed statistically using SPSS 17 software which included the paired $t$-test and the Mann-Whitney test. A probability value of less than 0.05 was considered significant. With this sample size the power of the study was 0.66 to detect an 0.05 significance level if the true difference between the means was 1. Reliability statistics using Cronbach's alpha for 13 closed ended questions was 0.815 .

\section{Results}

Compared with their peers in the study, students in the simulator group were significantly more likely to define the steps of cesarean section ( $91 \%$ vs $61.5 \%$ ), and were comfortable in assisting cesarean section (100\% vs $46.15 \%$ ) as they were able to identify the layers of abdomen opened during cesarean section. Twelve students $(100 \%)$ in the simulator group were able to identify the basic instruments for the procedure compared with only 3 of 13 in the control group of students $(23 \%)$. When asked whether they felt ready to close the rectus sheath and skin under supervision, 12 students $(100 \%)$ in the simulator group indicated that they felt confident that they could perform the procedure with minimal supervision or independently, compared with only 2 of 13 in the control group of students (15.3\%) (Table 1$)$.
All 12 students reported this as an excellent experience. All 12 students said that they would recommend such training for all their colleagues and juniors.

\section{Discussion}

Students who practiced cesarean section on an obstetrics simulator reported higher levels of confidence in their skills to assist cesarean section and perform abdominal closure during cesarean section under minimal supervision. Ninety-one percent of the respondents strongly agreed that the training was a valuable use of their break time, believed it would help them provide better patient care, and would recommend the training to their juniors. Students reported an increase in willingness and preparedness to carry out surgery after the training. Comments from participants included: 'Improvement themes related to wanting longer duration of training' One participant felt 'I could learn how to hold the knife in a proper way today'. The present study is a pilot study to assess the value of a cesarean section model in resident education. The sample size was chosen as students come in batches of 12 to 13 for their postings. A major advantage of this simulator training for relative surgical 'novices' is that the skills are taught by experts in a low-key, nonpressurized environment rather than in the operating room, where time pressures and patient safety are paramount. Ericsson ${ }^{7}$ and others ${ }^{8}$ have pointed out that learning is enhanced in low-tension environments, but high-level tension, such as is often found in the operating room, inhibits learning of motor skills because of associated anxiety. Simulation has been widely used in the military, the airline industry, and

Table I Student responses in both simulator and control groups

\begin{tabular}{|c|c|c|c|}
\hline Response & $\begin{array}{l}\text { Simulator trained } \\
\text { group }(n=12)\end{array}$ & $\begin{array}{l}\text { Control } \\
\text { group }(n=13)\end{array}$ & $P$ value \\
\hline Can prep and drape a surgical patient & $12(100 \%)$ & $3(23 \%)$ & $<0.0001$ \\
\hline $\begin{array}{l}\text { Recognize and name basic } \\
\text { surgical instruments }\end{array}$ & $12(100 \%)$ & $3(23 \%)$ & $<0.0001$ \\
\hline Define the steps of cesarean section & I I (9l.6\%) & $8(61.5 \%)$ & 0.031 \\
\hline $\begin{array}{l}\text { Identify the layers of the abdomen } \\
\text { during cesarean section }\end{array}$ & $12(100 \%)$ & $4(30.76 \%)$ & $<0.0001$ \\
\hline Take a skin incision & $12(100 \%)$ & $7(53 \%)$ & 0.015 \\
\hline Comfortable in delivering the head & 7 (58.3\%) & $6(46.15 \%)$ & 0.05 \\
\hline $\begin{array}{l}\text { Comfortable delivering and examining } \\
\text { the placenta }\end{array}$ & $7(58.3 \%)$ & $6(46.15 \%)$ & 0.05 \\
\hline Perform uterine closure & $7(58.3 \%)$ & $7(53.84 \%)$ & 0.057 \\
\hline Perform a subcuticular closure & $10(83.3 \%)$ & $4(30 \%)$ & 0.008 \\
\hline Perform a simple interrupted closure & II (9l.6\%) & $5(38.46 \%)$ & 0.006 \\
\hline Perform abdominal closure & $12(100 \%)$ & $6(46.15 \%)$ & 0.003 \\
\hline Comfortable in assisting cesarean section & $12(100 \%)$ & $6(46.15 \%)$ & 0.003 \\
\hline $\begin{array}{l}\text { Am ready to close rectus sheath and skin } \\
\text { under resident supervision }\end{array}$ & $12(100 \%)$ & $2(15.3 \%)$ & $<0.0001$ \\
\hline
\end{tabular}

Note: $P$ value $<0.05$ was statistically significant. 
now in medical specialties. Simulation attempts to recreate scenes to teach, test, and prepare for a particular scenario one may encounter. ${ }^{9}$

However, unlike other high-fidelity models, our model is inexpensive. The expense report for our entire project was US\$500 and allowed for participation of 25 residents for 2 days. The cost of surgical simulation systems can be anywhere from US\$4,000 to US\$200,000. ${ }^{10}$ In an era of shrinking budgets, easy availability and affordable cost are advantages of our simulation model. Surgical skills training on low-fidelity bench models was as effective as high-fidelity model training for the acquisition of technical skill among novice surgeons. Both low- and high-fidelity bench model training were superior to didactic training. ${ }^{11}$ The ultimate purpose of any surgical simulation is to help surgeons reach a skill level that will translate into improved surgical performance in the operating room. The current study does not address this issue. Simulation provides a safe environment, in which mistakes are tolerated without harming patients and appropriate responses can be learned and practiced. A more confident student should lead to less anxiety for not only the student but also for the patient and the teacher-physician. Any surgical simulator should be considered only as a complementary tool to accelerate learning and not as a replacement for an actual patient encounter, which is the cornerstone of medical education.

Limitations of the study are the small sample size, subjective survey, and lack of objective evidence of improved surgical performance. Studies need to be done with a larger sample size. Despite the limitations, our pilot study suggests that this simulation model is a good teaching model that utilizes modest resources. Identifying more effective methods to teach and assess surgical skills will benefit not only our trainees but also the patients for whom we care.

\section{Conclusion}

We were able to construct an inexpensive cesarean section trainer that facilitates instruction in cesarean section technique in a low-stress environment. Training sessions using this simulation improved students' perception of their technical knowledge and comfort level. This is an inexpensive, safe and efficient way to teach these surgical skills. Further studies still need to be done with a larger sample size.

\section{Acknowledgment}

We would like to thank Col Dr CG Wilson Principal, Kamineni Institute of Medical Sciences for his support and encouragement. We express sincere thanks to faculty members for their help and medical students for their active participation. We would like to thank the management of Kamineni Institute of Medical Sciences for their constant support and encouragement.

\section{Disclosure}

The authors report no conflicts of interest in this work.

\section{References}

1. Nishisaki A, Keren R, Nadkarni V. Does simulation improve patient safety? Self-efficacy, competence, operational performance, and patient safety. Anesthesiol Clin. 2007;25:225-236.

2. Tache S, Mbembati N, Marshall N, Tendick F, Mkony C, O'Sullivan P. Addressing gaps in surgical skills training by means of low-cost simulation at Muhimbili University in Tanzania. Hum Resour Health. 2009;27:64.

3. Reznick RK, MacRae H. Teaching surgical skills changes in the wind. N Eng J Med. 2006;355:2664-2669.

4. Hammoud MM, Nuthalapaty FS, Goepfert AR, et al. To the point: medical education review of the role of simulators in surgical training. Am J Obstet Gynecol. 2008;199:338-343.

5. Gardner R. Simulation and simulator technology in obstetrics: past, present and future. Expert Rev Obstet Gynecol. 2007;2:775-790.

6. Seibel BE, Best KA. Glue and grommets: A realistic c-section simulation for ObGyn training. OBG Management. 2008;20:No. 09.

7. Ericsson KA. The acquisition of expert performance: an introduction to some of the issues. In Mahwah NJ, editor. The road to excellence: the acquisition of expert performance in the arts and sciences, sports, and games. New York: Lawwrence Erlbaum Associates; 1996:1-50.

8. Pellegrini CA. Surgical education in the United States: navigating the white waters. Ann Surg. 2006;244:335-342.

9. Macedonia CR, Gherman RB, Satin AJ. Simulation laboratories for training in obstetrics and gynecology. Obstet Gynecol. 2003;102: 388-392.

10. Thomas MB, Dandolu V, Caputo P, Milner R, Hernandez E. Resident education in principles and technique of bowel surgery using an ex-vivo porcine model. Obstet Gynecol Int. 2010 doi:10.1155/2010/852647.

11. Grober ED, Hamstra SJ, Wanzel KR, et al. The educational impact of bench model fidelity on the acquisition of technical skill: the use of clinically relevant outcome measures. Ann Surg. 2004;240:374-381.
Advances in Medical Education and Practice

\section{Publish your work in this journal}

Advances in Medical Education and Practice is an international, peerreviewed, open access journal that aims to present and publish research on Medical Education covering medical, dental, nursing and allied healthcare professional education. The journal covers undergraduate education, postgraduate training and continuing medical education
Submit your manuscript here: http://www.dovepress.com/advances-in-medical-education-and-practice-journal

\section{Dovepress}

including emerging trends and innovative models linking education, research, and healthcare services. The manuscript management system is completely online and includes a very quick and fair peer-review system. Visit http://www.dovepress.com/testimonials.php to read real quotes from published authors. 